\title{
Direito Linguístico: olhares sobre as suas fontes
}

\author{
Linguistic rights: glances at its sources
}

\author{
Ricardo Nascimento Abreu* \\ Universidade Federal de Sergipe (UFS) \\ São Cristóvão, Sergipe, Brasil.
}

Resumo: O Direito Linguístico como um campo de estudos e pesquisas que se ocupa, dentre outras questões, da produção, aplicação e análise das normas que tutelam as línguas e os direitos de uso dessas línguas pelos indivíduos e grupos falantes, minoritários ou não, carece de uma teoria geral que consiga estabelecer parâmetros científicos de análise, amparados principalmente na ciência Linguística e no Direito. Trata-se, pois, de exigência incontornável para viabilizar a elaboração e o estudo de políticas linguísticas estatais e/ou paraestatais que atuem no universo das regulamentações intra e inter linguísticas, bem como no que diz respeito à mediação dos conflitos linguísticos que emergem por conta das relações de poder que se manifestam em contextos plurilíngues. Neste texto, buscaremos apresentar e discutir as principais fontes do Direito Linguístico e as suas dinâmicas de funcionamento nas diferentes esferas de organização política dos Estados, quer tomados em conjunto, no âmbito das Nações Unidas e no Direito Internacional dos Direitos Humanos, quer por meio do estudo das suas normas particulares (constitucionais e infraconstitucionais), sem deixarmos de lado uma perspectiva com enfoque no pluralismo jurídico, ao incluirmos, no rol dessas fontes, os costumes linguísticos das comunidades minoritárias falantes de idiomas em situação de vulnerabilidade.

Palavras-chave: Direito Linguístico. Fontes do Direito Linguístico. Teoria do Direito linguístico. Políticas linguísticas. Conflitos linguísticos.

Abstract: The Linguistic rights as a field of studies and research that deals, among other issues, with the production, application, and analysis of the norms that protect languages and the rights of use of these languages which are speaking by individuals and groups, minorities or not, needs a general theory that manages to establish scientific parameters of analysis, supported mainly in Linguistic Science and Law. It is, therefore, an essential requirement to make feasible, the elaboration and study of state and/or para-state linguistic policies that act in the universe of intra and interlinguistic regulations, as well as concerning the mediation of linguistic conflicts that arise on account of the power relations that manifest themselves in plurilingual contexts. In this text, we will seek to present and discuss the main sources of linguistic law and their dynamics of operation in the different spheres of the political organization of States, whether taken together, within the scope of the United Nations and international human rights law or through the study of their particular norms (constitutional and infraconstitutional), without leaving aside a perspective with a focus on legal pluralism by including in the list of these sources the linguistic customs of minority communities who speak languages in a vulnerable situation.

Keywords: Linguistic rights. Sources of linguistic rights. Theory of linguistic rights. Language policy. Language conflicts

\section{INTRODUÇÃO}

No clássico livro Linguagem, indivíduo e sociedade, organizado por Peter Burke e Roy Porter, somos alertados, já nas primeiras linhas introdutórias, que "A linguagem é tão íntima da existência [humana] que tem sido há muito negligenciada por historiadores”. Ainda que tal afirmação não possa ser estendida plenamente para outros campos do

\footnotetext{
* Doutor em Letras (UFBA). Professor da Universidade Federal de Sergipe (UFS), São Cristóvão/UFS. Email: tennascimento@gmail.com.
} 
conhecimento que não tomam as línguas como seu objeto principal de análise, a exemplo da Antropologia e da Sociologia, mas que também se dedicam, respectivamente, a compreender as práticas humanas e as relações de poder que se revelam pela linguagem, é certo que, para a ciência do direito, em grande proporção, a ideia de linguagem ainda é tomada quase sempre como sinônimo de instrumento de comunicação e expressão, sendo ainda pouco reconhecido o potencial dos idiomas de serem, eles mesmos, objetos jurídicos tutelados pelos Estados.

$\mathrm{Na}$ esteira da negligência apontada por Burke e Porter (1993), a ideia da proteção jurídica das línguas (minoritárias ou não) e dos seus falantes ainda é palco gerador de estranhamentos, desconhecimentos e rejeições em diversos círculos jurídicos e científicos, da mesma forma que a necessidade de intervenção estatal na mediação e resolução de conflitos linguísticos e na formulação de políticas de gestão das línguas ainda é recebida com bastante ceticismo.

Nas últimas décadas do século XX e nos primeiros anos do século XXI testemunhamos um crescente interesse da comunidade internacional e dos Estados nacionais na proteção e defesa dos direitos das minorias e dos grupos vulneráveis. Os chamados "novos direitos" que, via de regra, correspondem, entre outros, à proteção da infância, dos idosos, das pessoas LGBTQI+ e das mulheres são retratos prototípicos desse movimento jurídico que tem feito uso extremamente produtivo da hermenêutica e de princípios do direito que são extremamente caros à condição humana, a exemplo da dignidade e da igualdade.

O reconhecimento da necessidade de proteção jurídica das línguas e dos seus falantes por meio de um conjunto de princípios e normas comuns capazes de nortear a atividade jurisdicional dos Estados é inaugurado após a tessitura e promulgação da Declaração Universal dos Direitos Humanos e do término da Segunda Guerra Mundial. Lançavamse, a partir desses marcos jurídico e histórico, as bases para o desenvolvimento de um novo campo de conhecimento, qual seja: o Direito Linguístico.

Carente de uma teoria geral que norteie as ações executivas, legislativas e jurisdicionais dos Estados, bem como as pesquisas e os pesquisadores que se debruçam sobre a temática, o Direito Linguístico, principalmente no Brasil, vive um período no qual o seu próprio objeto ainda se apresenta de forma translúcida. A necessidade de conhecer simultaneamente aspectos teóricos e metodológicos da ciência do Direito e da linguística, estendendo-se de forma não rara para questões que permeiam a Teoria Política, a História, a Sociologia e a Antropologia, faz com que o campo do Direito Linguístico se configure como uma área extremamente pantanosa e desafiadora para gestores, operadores do direito e pesquisadores, sejam eles debutantes ou experimentados.

Já é possível, no entanto, vislumbrarmos um esforço mútuo de operadores do direito, Vitorelli (2015), Soares (2019); de profissionais e estudantes vinculados a instituições de pesquisa, Abreu (2012, 2016.a, 2016.b e 2019), Rodrigues (2018), Silva (2019) e de instituições não governamentais ativistas das políticas linguísticas, a exemplo do Instituto de Investigação e Desenvolvimento em Política Linguística - IPOL, com o intuito de, entre outras questões, mapear o Direito Linguístico, identificando os parâmetros por meio dos quais será possível falarmos na existência de um campo de estudos dotado de teoria(s) 
que seja(m) capaz(es) viabilizar um trabalho de concepção e implementação e análise de normas geradoras de políticas garantidoras da cidadania linguística a todos os brasileiros.

O presente texto objetiva contribuir com esse esforço conjunto de construção dos elementos basilares de uma teoria geral do Direito Linguístico, apresentando e discutindo, de forma sistemática, as principais fontes constitutivas desse campo de pesquisas, proporcionando uma classificação das normas jurídicas regulatórias que envolvem as políticas de uso, proteção e fomento das línguas pelas populações, com foco nas dinâmicas de tutela e proteção das línguas e dos direitos dos indivíduos e dos grupos de utilizarem essas línguas, em situações formais e/ou informais, regidas pelos Estados nacionais (ou não) nos quais esses idiomas estão circunscritos.

Ainda que não se possa falar na existência de um rol exaustivo, entendemos que a maioria absoluta das normas jurídicas que tratam das línguas e dos direitos dos seus falantes podem ser reunidas em torno das seguintes fontes: a. Direito Internacional dos Direitos Humanos - DIDH; b. Direito Constitucional e princípios constitucionais dos Estados nacionais; c. Direito Infraconstitucional dos Estados nacionais; d. Direito Estrangeiro e Comparado; e. Jurisprudência dos tribunais e, por fim, os costumes das populações (minoritárias ou não) em relação às suas próprias línguas.

\section{O DIREITO LINGUÍSTICO COMO UM CAMPO DE ESTUDOS}

O ainda tímido estado da arte do Direito Linguístico no Brasil tem revelado uma tendência que aponta para o fato de os operadores do direito, de os pesquisadores e de os ativistas político-linguísticos conceberem o campo a partir de duas vertentes:

a. Uma primeira vertente que privilegia o estudo dos direitos linguísticos em espécie, ou seja, assume, por um olhar stricto, a expressão "direitos linguísticos" e busca verificar, em suas pesquisas, o atendimento ou não das normas jurídicas existentes, por parte dos Estados nacionais.

b. Uma segunda vertente que toma, por um viés lato, a expressão "direito linguístico", e busca compreender as bases constitutivas de uma Teoria do Direito Linguístico, por meio da qual seja possível realizar uma análise da pertinência e da eficácia das normas existentes, bem como balizar o trabalho daqueles agentes envolvidos na concepção, implementação e usufruto das políticas emanadas dessas normas.

Reconhecendo-me como um pesquisador com forte aderência à segunda vertente e buscando contribuir com a imperativa agenda de constituição de uma teoria do Direito Linguístico, tenho desenvolvido, ao longo da última década, estudos com a finalidade identificar, sob os auspícios metodológicos da Linguística e da ciência do Direito, os aspectos basilares e constitutivos desse arcabouço teórico que possam ser aplicados aos mais diversos contextos de políticas linguísticas sejam elas políticas declaradas, percebidas ou praticadas (SOUZA; ROCA, 2015). 
Como consequência dessa trajetória de pesquisa e, levando-se em consideração as valiosas colaborações de colegas pesquisadores nacionais e estrangeiros, busquei recentemente, no dossiê temático - Políticas linguísticas críticas em contextos coloniais e pós-coloniais, da Revista da ABRALIN ${ }^{1}$, apresentar um conceito que fosse capaz de traduzir aquilo que compreendo atualmente como sendo a tarefa e o objeto do Direito Linguístico.

O campo dos direitos linguísticos, diferentemente daquilo que muitos ainda pensam, não se constitui apenas por uma lista de direitos individuais e/ou coletivos aos quais as pessoas fazem jus. Mais que isso, diz respeito a uma Teoria dos Direitos Linguísticos que fundamenta o estudo das normas de direito linguístico, quando estes estão vinculados aos direitos humanos, ao direito constitucional, ao direito administrativo etc. Interessa-se, igualmente, pelas fontes desse direito linguístico (direito internacional dos direitos humanos, direito constitucional, direito comparado, costumes das populações etc.); pela identificação de princípios aplicáveis a essas normas (territorialidade, personalidade etc.); pela identificação de metaprincípios geradores dessas normas (dignidade humana, igualdade etc.); pelas possibilidades hermenêuticas e de aplicação das normas de direito linguístico aos casos concretos, bem como pelas formas jurídicas de garantia de materialização desses direitos linguísticos a todos os seres humanos. (ABREU, 2019, p. 51-52)

Esse esforço na tentativa de elaboração de um conceito, que certamente será revisitado por outros pesquisadores cujas colaborações serão imprescindíveis para sua validação, retificação ou refutação, aparenta ser, por ora, capaz de apresentar os primeiros elementos por meio dos quais a tarefa de concepção de uma Teoria do Direito Linguístico poderá ser materializada. Por seu intermédio, por exemplo, já nos é possível confirmar que:

a. As normas de Direito Linguístico, a depender dos seus objetivos, têm o condão de tutelar interesses individuais, coletivos e difusos;

b. São objetos passíveis da tutela jurisdicional dos Estados, as línguas e os direitos dos indivíduos e dos grupos de utilizarem as suas línguas em situações formais e/ou informais da vida em comunidade;

c. As normas de Direito Linguístico possuem natureza jurídica polimórfica, pois apesar do seu forte alinhamento ao Direito Público, também é possível registrar sua presença em diversos ramos do Direito Privado;

d. Existem princípios gerais e específicos aplicáveis às normas e aos casos concretos que versam sobre o Direito Linguístico;

e. É possível identificar, ainda que em rol não exaustivo, as principais fontes das normas de Direito Linguístico.

${ }^{1} \underline{\text { http://revista.abralin.org/index.php/abralin/issue/view/78 }}$ 


\section{AS FONTES DO DIREITO LINGUÍSTICO}

Entendemos que o Direito Linguístico é constituído por uma variedade de normas que se encontram distribuídas difusamente por vários ramos do Direito. Há momentos em que se revelam como pertencentes ao arcabouço normativo dos Direitos Humanos, por vezes mostram-se com um perfil de Direito Constitucional e, não raro, revelam-se como normas de cunho processual. Desse modo, a compreensão das suas fontes principais se revela como um elemento fundamental no processo de análise normativa do Direito Linguístico, uma vez que, conhecendo o seu nascedouro e a sua vinculação jurídica, é possível ao pesquisador revelar um conjunto importante de informações a respeito dessa norma, como, por exemplo, os princípios a ela aplicados, seu alcance, eficácia e exigibilidade.

Segundo Portela (2011), é possível dividirmos as fontes do direito em dois grandes grupos: as materiais e as formais. Enquanto no primeiro caso deparamo-nos com normas cuja criação e conteúdo foram motivados por fatos históricos, ou fundamentos sociológicos, políticos, morais ou econômicos, as fontes formais representam o elemento axiológico que norteia o modo de revelação e exteriorização da norma jurídica adstrita a um conjunto de valores que orbitam em torno de um determinado ramo do Direito.

O estudo das fontes formais do Direito linguístico nos remete a um território devidamente consolidado e constituído pelos mais diversos ramos do Direito Positivo. Significa, pois, garimpar as normas que tutelam as línguas e os direitos dos falantes dessas línguas nos mais diversos campos da ciência jurídica. Por outro lado, as fontes materiais do Direito Linguístico, intimamente ligadas às práticas culturais das comunidades de fala, somente se revelam por meio de pesquisas de cunho majoritariamente sociológico e/ou antropológico, pois se tratam de normas criadas e geridas no seio das próprias comunidades, representando, por vezes, sistemas jurídicos paralelos ao ordenamento estatal.

Passemos, dessa forma, a apresentar as principais fontes do Direito Linguístico sem, no entanto, ostentar a pretensão de exaurir as possibilidades de existência de outras fontes, de natureza formal ou material.

\subsection{DIREITO INTERNACIONAL DOS DIREITOS HUMANOS}

O Direito Internacional dos Direito Humanos, doravante DIDH, certamente figura como a fonte contemporânea mais produtiva dos Direitos Linguísticos. Conforme já pontuamos anteriormente, o final da Segunda Guerra Mundial e a promulgação da Declaração Universal dos Direitos Humanos representaram uma ruptura paradigmática na produção de normas afeitas ao Direito Linguístico, pois pela primeira vez na história da humanidade, as questões linguísticas foram elevadas ao estatuto de Direito Humano e os conflitos linguísticos de toda natureza passaram a ter instrumentos jurídicos que influenciaram os modelos estatais de gestão das suas línguas em uma linha relativamente homogênea. Cumpre recordarmos que, no período anterior à criação da $\mathrm{ONU}$, as políticas de gestão das línguas, executadas por vários países ao redor do globo contemplavam, não 
raro, processos deliberados de enfraquecimento, proibição de uso e, como consequência direta ou indireta, a extinção de línguas em seus territórios.

O estudo das normas de Direito Linguístico presentes no DIDH já vem sendo realizado por um amplo espectro de pesquisadores que buscam de demonstrar a adesão ou a omissão dos Estados nacionais à proteção das línguas e das comunidades minoritárias falantes de idiomas em situação de vulnerabilidade, bem como compreender os mecanismos de proteção da diversidade linguística nos sistemas global e regionais de proteção dos Direitos Humanos.

Assim, a título de ilustração, Abreu (2012), em pesquisa intitulada "Os direitos humanos linguísticos no cenário do Direito Internacional”, analisou os principais instrumentos de Direito Internacional vinculados à Organização das Nações Unidas e voltados para a proteção das línguas e das minorias linguísticas, a exemplo dos pactos, tratados, comissões, convenções e declarações, com o intuito de compreender a forma como a questão da pluralidade e a proteção das minorias linguísticas estava sendo desenvolvida e aplicada no âmbito da ONU e dos Estados membros dessa organização.

Mais recentemente, Silva (2019), na pesquisa de doutoramento pela Universidade Federal de Santa Catarina, "Direitos Linguísticos dos povos indígenas no acesso à justiça: a disputa pelo direito ao uso das línguas indígenas em juízo a partir da analise de três processos judiciais", recorreu a diversos instrumentos do DIDH tais quais a Convenção 169 da OIT, a Declaração da ONU sobre os direitos dos povos indígenas, a Declaração americana sobre os direitos dos povos indígenas, a Declaração Universal dos Direitos Linguísticos e a Declaração sobre os direitos das pessoas pertencentes a minorias nacionais, ou étnicas, religiosas e linguísticas, para comprovar que a República Federativa do Brasil descumpre compromissos jurídicos firmados perante a comunidade internacional e viola direitos humanos dos indígenas brasileiros, mitigando o princípio constitucional de acesso à justiça ao impedir que eles possam escolher a língua por meio da qual se dirigirão às cortes nacionais.

$\mathrm{E}$, por fim, ainda no conjunto de trabalhos que se servem do DIDH como fonte do Direito Linguístico, destaco aqui as pesquisas em andamento das mestrandas Lia Nara Figuerêdo da Silva e Januária Pereira da Silva Rocha, do Programa de Pós-Graduação em Letras da Universidade Federal de Sergipe, por meio das quais elas buscam estudar o tratamento dos direitos linguísticos junto à Comissão Interamericana de Direitos Humanos - CIDH, tanto no conjunto das denúncias admitidas quanto naquelas que foram inadmitidas por essa comissão.

Com o protagonismo assumido pelas Nações Unidas em matéria proteção das minorias linguísticas no âmbito internacional, não restam dúvidas de que o DIDH permanecerá sendo uma das fontes mais promissoras do Direito Linguístico, especialmente no que diz respeito às normas que tomam esses direitos como Direitos Humanos. Nesse sentido, defender as línguas e as minorias linguísticas por meio de normas vinculadas aos Direitos Humanos faz com que essas normas passem a usufruir, imediatamente, das características inerentes a esses direitos, tais quais exemplificativamente citamos: a universalidade; a inerência; a transnacionalidade; a indisponibilidade; a inalienabilidade; a irrenunciabilidade; a imprescritibilidade; a 
indivisibilidade, interdependência e complementariedade; a primazia da norma mais favorável e caráter não exaustivo das listas de fatores de discriminação ${ }^{2}$.

\title{
3.2 DIREITO CONSTITUCIONAL E OS PRINCÍPIOS CONSTITUCIONAIS
}

Pensar o ramo do Direito Constitucional como fonte do Direito Linguístico significa reconhecer a sua posição estratégica entre o Direito Internacional e o direito infraconstitucional dos Estados nacionais. Significa também reconhecer que as normas jurídicas que compõem as constituições dos países exercem forte influência sobre as demais normas do ordenamento jurídico pátrio no que diz respeito à sua hermenêutica e a sua própria constitucionalidade, em um processo conhecido pelo nome de filtragem constitucional ou constitucionalização do direito.

\begin{abstract}
A ideia de constitucionalização do direito aqui explorada está associada a um efeito expansivo das normas constitucionais, cujo conteúdo material e axiológico se irradia, com força normativa, por todo o sistema jurídico. Os valores, os fins públicos e os comportamentos contemplados nos princípios e regras da Constituição passam a condicionar a validade e o sentido de todas as normas do direito infraconstitucional. (BARROSO, 2014, p. 379).
\end{abstract}

Desse modo, podemos perceber que a inserção de temáticas vinculadas ao Direito Linguístico nas constituições dos países deve ser considerada como ação estratégica no processo de formulação de políticas de proteção das línguas e das minorias linguísticas, especialmente, quando tais inserções forem realizadas junto ao rol dos direitos fundamentais.

Um levantamento realizado pela UNESCO e compilado por Russell e Cohn (2012) demonstra que, após a promulgação da Declaração Universal dos Direitos Humanos, houve uma verdadeira corrida dos países no sentido de constitucionalizar a matéria referente às suas línguas oficiais. Tal entusiasmo infelizmente não se seguiu, em muitos casos, em relação aos processos de nacionalização daquelas línguas não alçadas à condição de idiomas oficiais.

São diversos os exemplos de países cujas línguas não oficiais sequer possuem estatuto jurídico declarado na Constituição, configurando-se como línguas em situação de indigência jurídica e de extrema condição de vulnerabilidade. Em maior ou menor grau, essa indigência jurídica pode ser encontrada nas línguas que possuem pouco prestígio social, a exemplo das línguas indígenas, as línguas de imigração e, mais recentemente, as línguas das comunidades de refugiados.

A Constituição pode ser retratada como um espelho da existência e da eficácia de políticas de garantia de Direitos Linguísticos pelos cidadãos de um determinado país. Diante do seu silenciamento perante à questão desses direitos, mas audíveis simbolicamente serão os conflitos linguísticos existentes entre as minorias linguísticas outsiders e aqueles que representam a maioria usuária das línguas do/no poder.

\footnotetext{
${ }^{2}$ Para melhor compreensão das características das normas de Direitos Humanos sugerimos a leitura de Portela (2011).
} 
Outro elemento que se coloca de forma estratégica quando pensamos nas fontes do Direito Linguístico, no âmbito das constituições dos Estados, são os princípios constitucionais. Tenho realizado em minhas pesquisas forte defesa no sentido de que, nos casos dos países cujas constituições silenciaram em relação à explicitude das normas constitucionais de Direito linguístico, há que se investir na hermenêutica dos princípios como forma de suprir tais lacunas constitucionais. Em conformidade com o nosso entendimento, metaprincípios constitucionais a exemplo da dignidade humana e da igualdade podem apresentar uma produtividade bastante elevada para os pesquisadores e operadores do direito nos processos de omissões das constituições no tocante às questões de Direito Linguístico.

\subsection{O DIREITO ESTRANGEIRO E COMPARADO}

Não há dúvidas de que as experiências exitosas de outros países no que diz respeito à elaboração de normas de Direito Linguístico e ao processo de gestão dos cenários plurilíngues existentes em seus territórios podem representar um terreno fértil às possibilidades de aprendizado e incorporação das boas práticas nas rotinas dos Estados menos desenvolvidos em matéria de promoção e proteção dos Direitos Linguísticos das populações minoritárias.

Países como Canadá, Índia, Peru e México possuem histórias exitosas na gestão do multilinguismo em seus territórios e a análise dos seus ordenamentos jurídicos e das políticas linguísticas implementadas com sucesso podem servir para guiar o trabalho de elaboração legislativa e de gestão de políticas linguísticas em Estados que possuem pouca expertise nesse modelo de gestão.

Do mesmo modo, a comparação entre os sistemas jurídicos dos países, quer de mesma família jurídica, quer de famílias diferentes, pode se revelar como um produtivo método para a compreensão e proposição de modelos de gestão linguística, baseando-se, para isso, nas semelhanças e divergências, viabilidades e inviabilidades de pensar e executar políticas linguísticas baseadas em normas que se mostraram eficazes ou ineficazes nos cenários para os quais foram originalmente concebidas.

Assim, a título de exemplificação, é possível pensarmos que determinadas políticas linguísticas fundamentadas em normas que levam em consideração o princípio da territorialidade sejam efetivas em determinados cenários, mas ineficazes em contextos que exigem que o fundamento da norma esteja baseado no princípio da personalidade.

Desse modo, importa alertar ao pesquisador, ao legislador, ao operador do direito e ao gestor público de políticas linguísticas que o estudo das normas de Direito Linguístico estrangeiro ou a comparação entre sistemas jurídicos distintos requer a devida criticidade e cuidados, pois o mero transplante de normas e/ou políticas públicas sem as devidas ponderações poderão acarretar mais prejuízos que benefícios para a proteção da diversidade linguística do Estado receptor. 


\subsection{DIREITO INFRACONSTITUCIONAL}

O direito infraconstitucional representa um forte manancial de normas atinentes ao Direito Linguístico. Entre todas as fontes até aqui listadas, as normas infraconstitucionais de Direito Linguístico são aquelas que se apresentam da forma mais difusa, estando espalhadas por praticamente todos os diplomas normativos dos Estados nacionais.

Tomando o Estado brasileiro como exemplo, é possível mapear a existência dessas normas no direito penal, civil, administrativo, cultural, educacional e do trabalho. De igual maneira, no âmbito processual, tais normas também podem ser registradas no direito processual civil, penal, administrativo e trabalhista.

$\mathrm{Na}$ produção legislativa, é possível verificar a existência de leis infraconstitucionais produzidas no âmbito dos entes federativos e que têm como escopo principal a matéria da proteção e gestão das línguas, bem como dos direitos dos indivíduos e dos grupos pertencentes a comunidades linguísticas minoritárias. O Decreto Presidencial 7.387/2010, que instituiu o Inventário Nacional da Diversidade Linguística; as leis municipais de cooficialização de línguas e a Lei $\mathrm{N}^{\circ}$ 10,436/2002 que dispõe sobre a Língua Brasileira de Sinais - Libras e dá outras providências, são exemplos prototípicos dessa atividade legislativa em torno da gestão das línguas no território brasileiro.

O conjunto das pesquisas representativas do estado da arte sobre o Direito Linguístico no Brasil já nos permite registrar que a ausência de uma teoria capaz de nortear os trabalhos legislativos de produção das normas infraconstitucionais de Direito Linguístico tem gerado danos por vezes incontornáveis na concepção, elaboração, implementação e avaliação das políticas publicas que dizem respeito ao cenário multilíngue nacional, podendo acarretar, em última análise, até mesmo o desaparecimento de um quantitativo significativo de línguas brasileiras em um período de tempo relativamente curto.

\subsection{JURISPRUDÊNCIAS DOS TRIBUNAIS}

Já que uma das funções precípuas da existência de um conjunto de normas constitutivas de um campo do Direito dedicado às questões envolvendo os idiomas circunscritos aos territórios dos Estados nacionais é a busca pela pacificação dos conflitos linguísticos, é mais que natural concebermos a jurisprudência dos tribunais como uma fonte privilegiada do Direito Linguístico.

O conjunto de decisões dos tribunais que dão fim aos processos judiciais que têm nos aspectos linguísticos o seu objeto primário ou incidental é instrumento indispensável no processo de interpretação e renovação hermenêutica das normas de Direito Linguístico.

Em vários países, a exemplo do Brasil, a exiguidade de estudos que se debrucem sobre a análise jurisprudencial dos tribunais envolvendo as temáticas dos conflitos linguísticos fazem com que não tenhamos uma ideia muito definida sobre as formas pelas quais o aparato judicial lida com o Direito Linguístico. O trabalho de Vitorelli (2015) que 
versa sobre as minorias linguísticas no processo judicial brasileiro, juntamente com a pesquisa de Silva (2019) que se debruça sobre o acesso à justiça pelos povos indígenas brasileiros, nos dão bons indícios de que estamos bem distanciados das formas ideais de tratamento da diversidade linguística em juízo e que é preciso capacitar os órgãos policiais e judiciais do país para que possam lidar com a realidade plurilíngue nacional, garantindo os direitos de cidadania linguística de todos aqueles que busquem o amparo jurisdicional, independentemente da comunidade linguística da qual faça parte.

\subsection{COSTUMES DAS COMUNIDADES LINGUÍSTICAS}

Dentre as pautas contemporâneas de pesquisa em Direito Linguístico, as mais desafiadoras certamente são aquelas que envolvem a análise de normas contidas em sistemas jurídicos não estatais, pautados principalmente nos costumes das populações falantes de línguas minoritárias, uma vez que pesquisas dessa natureza normalmente exigem que os seus pesquisadores extrapolem os limites da pesquisa linguística e jurídica e busquem abrigo em outros campos do conhecimento, especialmente na pesquisa antropológica de natureza etnográfica.

São as pesquisas que se dedicam a explorar as normas de Direito Linguístico vinculadas aos costumes das comunidades que nos permitem compreender peculiaridades exclusivas desses grupos minoritários, evitando assim que políticas linguísticas homogêneas propostas pelo Estado resultem em verdadeiros fracassos exatamente por deixarem de considerar tais aspectos específicos e que somente fazem sentido da forma como foram concebidos e no seio da comunidade que os conceberam.

A pesquisa de Guerola (2018), que trata da demarcação de terras indígenas como política linguística, bem como a pesquisa em andamento da mestranda Josefa Felix do Nascimento (PPGL/UFS), que aborda os processos de formulação de politicas linguísticas em uma comunidade cigana em Sergipe, são excelentes exemplos de como a pesquisa etnográfica pode revelar aspectos deveras peculiares em relação às formas por meio das quais as comunidades linguisticamente minoritárias se organizam, organizam as suas práticas e as suas relações com o mundo, por meio dos seus idiomas.

\section{CONSIDERAÇÕES FINAIS}

No bojo dos chamados "novos direitos", o Direito Linguístico vem despontando como uma necessidade cada vez mais urgente na sociedade contemporânea, posto que estamos a testemunhar um acelerado processo de erosão da diversidade linguística, bem como um forte movimento de mitigação da cidadania dos indivíduos e dos grupos vinculados às línguas minoritárias do planeta.

Apesar de podermos associar o marco histórico do Direito Linguístico à promulgação da Declaração Universal dos Direitos Humanos, em 1848, até a presente data o campo ressente-se da ausência de uma teoria geral que seja capaz de nortear os trabalhos de concepção, implementação e avaliação de politicas linguísticas protagonizadas pelos Estados nacionais, no sentido de garantir direitos de cidadania 
linguística às pessoas e de fomentar e preservar a diversidade linguística em todos os aspectos da vida social, política, educacional etc.

Buscamos, nesse texto, apresentar as principais fontes do Direito Linguístico com o intuíto de contribuir na construção de um arcabouço teórico que seja capaz de nortear as ações e as pesquisas de todos aqueles que se interessam pela temática do Direito Linguístico.

Como as fontes do Direito Linguístico não podem ser agrupadas em um rol taxativo de possibilidades, limitamo-nos, nesse texto, a apresentar aquelas mais comumente encontradas e com as quais a maioria das políticas linguísticas são constituídas no Brasil e no mundo.

Cremos fidedignamente que o trabalho de construção de um pavimento teórico que possa subsidiar os trabalhos e as pesquisas em Direito Linguístico é tarefa que requer a colaboração de muitas mãos e, dessa maneira, fazemos votos verdadeiros para que mais pesquisadores possam se interessar pela temática, pois todos nós sabemos que o processo de silenciamento das línguas minoritárias avança em ritmo bastante acelerado no mundo inteiro e, com ele, corremos o enorme risco de perder culturas inteiras e formas únicas de ler o mundo.

\section{REFERÊNCIAS}

ABREU, R. N. Os Direitos Humanos Linguísticos no cenário do Direito Internacional. (Monografia de Graduação) - Curso de Direito da Universidade Tiradentes - UNIT, 2012.

ABREU, R. N; JACINTHO, J. M. M. Caminhos constitucionais para uma efetiva proteção das minorias linguísticas no Brasil. In: Guerra, Gustavo Rabay; Robl Filho, Ilton Norberto; Moraes Filho, José Filomeno de. (Orgs.). Teoria do Estado e da Constituição. Florianópolis: CONPEDI, 2014.

ABREU, R. N. Prolegômenos para a compreensão dos direitos linguísticos: uma leitura a partir da Constituição da República Federativa do Brasil, p. 161 -188. In: Sociolinguística e Política Linguística: olhares Contemporâneos. São Paulo: Blucher, 2016 a.

ABREU, R. N. Os direitos linguísticos: possibilidades de tratamento da realidade plurilíngue nacional a partir da constituição da República Federativa do Brasil de 1988. (Dissertação de Mestrado). Programa de Pós-Graduação em Direito da Universidade Federal de Sergipe. São Cristóvão: UFS, 2016 b.

ABREU, R. N. Estatutos jurídicos e processos de nacionalização de línguas no Brasil. Revista da ABRALIN, v. 17, n. 2, 30 jun. 2019.

BARROSO, L. R. Curso de Direito Constitucional contemporâneo: os conceitos fundamentais e a constituição do novo modelo. São Paulo: Saraiva, 2014. 
BARROSO, L. R. O novo direito constitucional brasileiro: contribuições para a construção teórica e prática da jurisdição constitucional no Brasil. Belo Horizonte: Fórum, 2014.

BRASIL. Constituição da República Federativa do Brasil. Brasília, DF: Editora do Senado,1988.

BRASIL. Supremo Tribunal Federal. A Constituição e o Supremo. Brasília, DF. 2015.

BRASIL. Decreto 7.387 de 09 de dezembro de 2010: Institui o Inventário Nacional da Diversidade Linguística e dá outras providências. Disponível em: http://www.planalto.gov.br/ccivil 03/ Ato2007-2010/2010/Decreto/D7387.htm.

Acesso em 10 fev 2020.

BURKE, P; PORTER, R. Linguagem, individuo e sociedade: história social da linguagem. São Paulo: Editora da Universidade Estadual Paulista, 1993.

DUARTE, C. S. Fundamentos filosóficos de proteção às minorias. In. JUBILUT, L. L.; BAHIA, A. G. M. F.; MAGALHÃES, J. L. Q. Direito à Diferença. São Paulo: Saraiva, 2013.

GUEROLA, C. A demarcação de terras indígenas como política linguística. Revista da ABRALIN, v. 17, n. 2,28 jun. 2019.

GUERRA, S. Direitos Humanos e Cidadania. São Paulo: Atlas, 2012.

JACINTHO, J. M. M. Dignidade humana: princípio fundamental. Curitiba: Juruá, 2009.

KYMLICKA, W. Politics in the vernacular: nationalism, multiculturalism, and citizenship. New Your: Oxford University Press, 2001.

KYMLICKA, W.; PATTEN, A. Language rights and political theory. New Your: Oxford University Press, 2007.

PORTELA, P. H. G. Direito Internacional Público e Privado: incluindo noções de Direitos Humanos e de Direito Comunitário. Salvador: Podium, 2011.

RICENTO, T.; PELED, Y.; IVES, P. Language policy and Political Theory: building bridges, assessing breaches. Switzerland, 2015.

RODRIGUES, F C. A noção de direitos linguísticos e a sua garantia no Brasil: entre a democracia e o fascismo. In. Lingua e instrumentos linguísticos, $\mathrm{N}^{\circ}$ 42, jul - dez 2018.

RUSSELL, J.; COHN, R. Linguistic rights. Scotland: Bookvika publishing, 2012.

SEGUÍN, E. Minorias e grupos vulneráveis: uma abordagem jurídica. Rio de Janeiro: Forense, 2002. 
SEGUÍN, E. (Coord.). Direito das minorias. Rio de Janeiro: Forense, 2001.

SILVA, J. I. Direitos linguisticos dos povos indígenas no acesso à justiça: a disputa pelo direito ao uso das línguas indígenas em juízo a partir da análise de três processos judiciais. (Tese de doutorado). Programa de Pós-Graduação em Linguística da Universidade Federal de Santa Catarina. Florianópolis: UFSC, 2019.

SOARES, I. V. P. Direito à diversidade linguística no Brasil e sua proteção jurídica. In. GARCIA, M. V. C. [et al.]. Seminário Ibero-americano de Diversidade Linguistica. Brasília: IPHAN, 2019.

SOUSA, S. C. T.; ROCA, M. d. P. Politicas linguísticas: declaradas, praticadas e percebidas. João Pessoa: Editora UFPB, 2015.

SOUZA NETO, C. P.; SARMENTO, D. A Constitucionalização do Direito: fundamentos teóricos e aplicações específicas. Rio de Janeiro: Lumen Juris, 2007.

VITORELLI, E. Minorias linguísticas no processo judicial brasileiro. In VITORELLI, E. (Org.). Temas atuais do Ministério Público Federal. Salvador: Podium, 2015.

WOLKMER, A. C.; LEITE, J. R. M. Os "novos" direitos no Brasil: natureza e perspectivas - uma visão básica das novas conflituosidades jurídicas. São Paulo: Saraiva, 2012.

WUCHER, G. Minorias: proteção internacional em prol da democracia. São Paulo: Juarez de Oliveira, 2000. 